\title{
Prevalence of Obesity amongst Staff and Students of a Tertiary Institution in Nigeria
}

\author{
Utoo Priscilla Mwuese ${ }^{1}$, Okpara Ihunanya Chinyere ${ }^{2}$ \\ Department of Community Medicine, P. M. B. 102119, Benue State University Makurdi, Nigeria. \\ Department of Internal Medicine, P. M. B. 102119, Benue State University Makurdi, Nigeria.
}

\begin{abstract}
:
Background: Obesity and overweight have reached epidemic levels in developed countries and the prevalence is rising in developing nations. This study seeks to determine the prevalence of obesity in a tertiary institution in Nigeria and its association with socio-demographic factors.

Method: In a cross-sectional survey, by a cluster sampling method, 471 subjects were selected between the ages of 16 - 68years. A structured questionnaire was used to collect socio-demographic data. The body weight (kg) and height (m) of subjects were measured and the body mass index (BMI) calculated.

Results: The prevalence of obesity was $9.1 \%$ and that of overweight was $26.2 \%$. Obesity was significantly associated with female gender $\left(\chi^{2}=27.884, p<0.001\right)$; age $<$ 40years $\left(\chi^{2}=25.915, p<0.001\right)$; being married $\left(\chi^{2}=46.819, p<0.001\right)$ and low socioeconomic status $\left(\chi^{2}=18.314, p=0.005\right)$. Obesity was not significantly associated with educational status $\left(\chi^{2}=5.404, p=0.145\right)$.

Conclusion: The determinants of obesity in this tertiary institution are female sex, young age, marriage and low socio-economic status.
\end{abstract}

Key words: Obesity, overweight, prevalence, socio-demographic, tertiary institution.

\section{Introduction}

Obesity and overweight abnormal are conditions in which weight gain has reached the point where it poses significant risk to health. This excessive fat build up results from an imbalance between calories consumed on one hand and calories expended on the other hand ${ }^{[1]}$. Obese individuals are therefore predisposed to adverse health conditions such as cardiovascular diseases, type 2 diabetes mellitus, osteoarthritis and cancers $^{[2,3]}$.

The World Health Organisation (WHO) estimated that by 2005, at least 1.6 billion and 400million people aged above 15 years were overweight and obese respectively. It further projected that by 2015 , these statistics will increase to 2.3 billion for overweight and 700 million for obesity unless drastic measures are $\operatorname{taken}^{[4]}$. In Africa, despite a high prevalence of undernutrition, the prevalence of overweight and obesity are increasing at an alarming rate. It is estimated that $25 \%$ to $60 \%$ of urban women in Africa are overweight ${ }^{[5]}$. In Nigeria a study carried out in 2008 , reported a prevalence of $3.2 \%$ for overweight and $0.5 \%$ for obesity among adolescents in Osun state ${ }^{[6]}$.

Obesity was previously a problem of high - income countries but is now dramatically on the rise in low and middle income countries, especially in urban settings ${ }^{[4]}$. The rise in the prevalence of overweight and obesity in these countries results from increased consumption of energy dense foods that are high in fat and sugars. This dietary change is referred to as the nutritional transition ${ }^{[7]}$. Besides the nutritional transition, obesity is also caused by decreased physical activity because of increasingly sedentary nature of many forms of work and changing methods of transportation and increasing urbanization ${ }^{[8-10]}$.

Obesity may be classified as generalized obesity or central obesity. In adults, the body mass index (BMI) is used as a measure of generalized obesity while waist circumference (WC) and waist to hip ratio are measures of central obesity. The BMI is calculated by dividing the weight in kilograms by the square of the height in meters ${ }^{[11]}$. The WHO classifies a BMI of $25 \mathrm{~kg} / \mathrm{m}^{2}-29.9 \mathrm{~kg} / \mathrm{m}^{2}$ as overweight while that of $30 \mathrm{~kg} / \mathrm{m}^{2}$ and above is classified as obese ${ }^{12}$. A BMI of $40 \mathrm{~kg} / \mathrm{m}^{2}$ and above is classified as morbid obesity ${ }^{[12]}$.

The prevalence of overweight and obesity and the comorbidities associated with them are well documented in developed countries. However the same cannot be said of developing countries. Obesity leads to increase in morbidity and mortality worldwide and it is important to have good understanding of the burden and distribution of the disease in our environment. More so it is necessary to assess the prevalence of overweight and obesity in a tertiary institution to see whether the nutritional transition has caught up with them as they are expected to know better than the rest of the society. This study sought to determine the prevalence of overweight and obesity in a tertiary institution in Nigeria and the socio-demographic determinants of obesity in this institution. 


\section{Materials And Method}

In a cross-sectional study of staff and students of the Benue State University aged 16 years and above, subjects were selected for the study between March 2011 and June 2011. The Benue State University is located in Makurdi town which is the most urbanised area in Benue state.

The various departments in the institution were considered as clusters and were subjected to simple random sampling to obtain the sample size.

Each of the subjects gave informed consent in written form before they were used for the study. Ethical approval was obtained from the ethical committee of the Benue State University before the study was carried out. Consented subjects who were pregnant or unwilling to remove their heavy garments for measurements were excluded from the study.

A structured questionnaire designed to obtain information regarding age, sex, marital status, educational level and salary scale was administered to the participants by trained assistants. The body weight was measured to the nearest $0.5 \mathrm{~kg}$ using a weighing scale with the participants wearing minimal clothing. Height was measured to the nearest $0.5 \mathrm{~m}$ using a stadiometer. The BMI was calculated by dividing the weight by the square of the height in meters ${ }^{[11]}$. The WHO diagnostic criteria was used in classifying the subjects as overweight and obese $\mathrm{e}^{[12]}$.

The data was analysed using the Statistical Packages for Social Sciences (SPSS) version 19 statistical software. For continuous variables, means and standard deviations were calculated and the means compared using the independent samples $t$ test. Cross tabulation was used to calculate prevalent rates and Pearson Chi Square was used to test the association between obesity and socio-demographic factors. Values of $p<0.05$ were considered statistically significant.

3.1 Demographic characteristics of the stud

\section{Results}

Therewere a total of 471 participants in the study aged $16-68$ years. Males were 315 in number while females were 156 in number. The mean age of the population was $28.65 \pm 9.10$ years. The mean age of the males was $28.83 \pm 9.38$ years while that of the females was $28.30 \pm 8.53$ years. With respect to gender, there was no significant difference in the mean age or weight of the participants. However there was a significant difference in the mean height and BMI of males versus females. Males were significantly taller than females $(p=0.010)$, while females had significantly higher BMI $(\mathrm{p}=0.001)$ than males. The majority of the study population were $\leq$ 35 years $(\mathrm{n}=374)$. These are shown in TABLE 1 and fig. 1 .

\subsection{Prevalence of obesity and overweight in the study population}

The prevalence of overweight was $26.2 \%$ and that of obesity was $9.1 \%$. Obesity was more prevalent in females than males with rates of $16.1 \%$ versus $5.7 \%$ respectively $(\mathrm{p}<0.001)$. The distribution of BMI in the study population was as follows: $1.7 \%$ were underweight, $63.0 \%$ had normal BMI, $26.2 \%$ were overweight and $9.1 \%$ were obese. This is shown in TABLE 2 . The prevalence of obesity peaked in the $26-35$ age group and that of overweight peaked in the $16-25$ age group. This is shown in fig. 2.

\subsection{Association with socio-demographic factors}

Obesity was significantly associated with young age. It occurred more in the younger age group that were less than 40years than in older age group of greater than or equal to 40 years $\left(\chi^{2}=9.141, p=0.002\right)$. It was significantly associated with female sex $\left(\chi^{2}=27.884, \mathrm{p}<0.001\right)$; being married $\left(\chi^{2}=46.819, \mathrm{p}<0.001\right)$; low socio-economic status $\left(\chi^{2}=18.314, \mathrm{p}=0.005\right)$. It was not significantly associated with educational status $\left(\chi^{2}=\right.$ $5.404, \mathrm{p}=0.145)$.

\section{Discussion}

The prevalence of obesity in this study was $9.1 \%$ and that of overweight was $26.2 \%$. It was more prevalent in females than males and also more prevalent in the younger age group than the older age group.

The obesity prevalence of $9.1 \%$ in this study is close to the $9.3 \%$ reported in Tanzania but higher than the $4.2 \%$ reported in a study done 6 years ago in Jos Nigeria. It is also higher than $7.2 \%$ in Nepal in Asia. However less than $16.4 \%$ in Australia and $34 \%$ in the United States of America (USA). ${ }^{[3,13-16]}$.

The prevalence of obesity in our study was low compared to developed and high income countries. This is probably because the majority of the population consisted of young people and mainly students,less than or equal to 35years who are usually trekking to their destination reducing the use of transport system and sedentary lifestyle. Students are usually physically active.

The male prevalence of obesity was $5.1 \%$ and the female prevalence was $16.1 \%$ and the difference was statistically significant. This female predominance agrees with studies from other developing nations like Iran, Tanzania, and Mauritius. Both sexes were almost equally affected in England, Germany and USA but in 
Australia, Italy and Nepal ${ }^{[15-17]}$, there was male predominance. In Nigeria, this female predominance agrees with the findings in Port Harcourt ${ }^{[18]}$, and Ibadan ${ }^{[19]}$. This may be related to gender differences in metabolism and hormonal balance ${ }^{[20,21]}$. Besides female students are increasingly susceptible to weight gain because they are less likely to engage in regular sporting activities partly due to lack of facilities that are gender sensitive. Also culturally females are constrained to taking care of domestic chores after school hours. Females are less likely to take a walk to their destination, preferring to be conveyed in vehicles.

The prevalence of obesity was more in the younger age group than in the older age group and the difference was statistically significant. Again this is likely due to the age distribution of the population as shown in fig. 1. The majority of the population is between $16-35$ years. This finding agrees with those of a study done at Ilorin Nigeria where the prevalence of obesity peaked in the $30-39$ age group ${ }^{[22]}$. Our study showed a peak in the $26-35$ age group (fig. 2). This may be an alert that young people are becoming obese and at older ages may become morbidly obese ${ }^{[12]}$ if not controlled. This may be a feature of the nutritional transition ${ }^{[7]}$. Early education of young people especially those in their teens and twenties about risk factors for obesity and its complications, will delay the onset of obesity. Obesity in childhood is frequently carried on to adulthood and is associated with cardiovascular disease risk factors such as dyslipidemia, hypertension, increase in left ventricular mass and type 2 diabetes mellitus ${ }^{[23-25]}$.

Our study showed that obesity was more prevalent in those with tertiary education or in a tertiary institution. This was because the study was carried out in a tertiary institution. This pattern differs from findings in some studies done in Australia and Spain ${ }^{[26,27]}$. Obesity was also associated with low socio economic status and this finding agrees with other studies done in South Africa and Mexico ${ }^{[28,29]}$.

Obesity was significantly associated with being married. Most females marry between the ages of $26-$ 35 years during which we had the peak prevalence of obesity. This is probably because married people eat a lot in the process of cooking for their husbands and are less likely to engage in sporting activities or take a walk.

\section{Conclusion}

The prevalence of obesity was $9.1 \%$ and that of overweight was $26.2 \%$. The socio-demographic determinants of obesity in this study were female sex, age $<40$ years, low socioeconomic status and marriage. These determinants should form the areas of focus for interventional measures such as health education and exercises to reduce the prevalence of obesity in tertiary institutions.

\section{Limitations}

Obesity was only assessed by body mass index alone.

\section{References}

[1]. World Health Organisation Expert Committee : Physical status, the use and interpretation of anthropometry. Report of a WHO expert Committee Technical report series 854, WHO Geneva, 1995.

[2]. Bakari AG, Onyemelukwe GC, Sani BG, Aliyu IS, Hassan SS et al. Obesity, Overweight and underweight in suburban northern Nigeria. Int J Diabetes and Metabolism 2007; $15: 68-69$.

[3]. Centers for Disease Control and Prevention (CDC). Obesity among adults in the United States; No statistically change since 2003 2004. Data brief Number 1. November $2007.8 \mathrm{pp}$. Available from: http://www,cdc.gov/nchs/data/databrief/db01.pdf

[4]. WHO Media Centre, author factsheet : Obesity and overweight 2006. Sep, http://www.who.inf/mediacentre/factsheet/fs311/en/index.html.

[5]. World Health Organisation, author. WHO Africa region : Global database on body mass index. 2008. http://apps.who.int/bmi/index.jsp

[6]. Olumakaiye MF. Prevalence of underweight : a matter of concern among adolescents in Osun state. Pakistan Journal of Nutrition. 2008; 7 (3) : $503-508$.

[7]. Borne LT, Lambert EV, Steyne K. Where does the black population of South Africa stand on the nutritional transition? Public Health Nutrition $2002 ; 5(1 \mathrm{~A}): 157-162$.

[8]. Tremblay MS, Katzmaryk PT, Wilms JD. Temporal trends in overweight and obesity in Canada $1981-1996$. Int J Obes Relat Metab Disord 2002; $26: 538-543$.

[9]. Stetler N, Bovet P, Shamlaye H, Zemet BS, Stallings VA et al. Prevalence and risk factors of overweight and obesity in children from Seychelles, a country in rapid transition : the importance of early growth. Int J Obes Relat Metab Disord 2002; $26: 214-219$.

[10]. Flegal KM, Carol MD, Kuckzmarski RJ, Johnson CL. Overweight and obesity in the United States : prevalence and trends $1960-$ 1964. Int J Obes 1998; $22: 39-47$.

[11]. Quetelet AD. Physique De 'LHomme, quoted by pengelly CDR. Body mass index and abdominal girth in the diagnosis of obesity. Proc. R Col Physicians, Edinburg 1994; $22: 39-47$.

[12]. World Health Organisation Technical report series 894 : Obesity : preventing and managing the global epidemic. Geneva : World Health Organisation 2000.

[13]. Puepet FH, Zoakah AI, Chuhwak EK. Prevalence of overweight and obesity among urban Nigeria adults in Jos. Highland Medical Research Journal 2002; 1:13 - 16.

[14]. Nyaruhucha CNM, Achen JH, Msuyu JM, Shayo WB, Kulwa KBM. Prevalence and awareness of obesity among people of different age groups in educational institutions in Morogoro, Tanzania. East African Medical 2003; 80: 68 - 72.

[15]. Vaidya AK, Pokharel PK, Nagesh S, Karki P, Kumar S et al. Association of obesity and physical activity in adult males in Dhahran, Nepal. KUMJ 2006; 4 : 192 - 197.

[16]. Australian Bureau of Statistics. National Health Survey. Summary of result Australia 2004 - 2005 (cat .no. 4364.0) 
[17]. The Australian and New Zealand Obesity Society (homepage on the internet) Obesity prevalence in several countries worldwide. c2008 (2007 February; cited on 2008 July $23^{\text {rd }}$ ) Available from: http://.www.asso.org.au/home/obesity/info/stats/worldwide.

[18]. Buowan Y. Obesity among students attending a tertiary institution in Nigeria. The internet journal of tropical medicine. 2010; 7(1): $102-109$.

[19]. Omogbodun OO, Adediran KI, Omogbodun AO, Adedokun BO, Esan O. Gender and rural - urban differences in the nutritional status of the in - school adolescents in western Nigeria. Journal of Biosocial Sciences 2010; 42 (5): 65 - 76.

[20]. Wisniewski AB, Chernausek SD. Gender in childhood obesity:Family environment, hormones and genes. Gend Med. 2009; 6 (suppl1): $76-85$.

[21]. Cameron N, Getz B. Sex differences in the prevalence of obesity in rural African adolescents. Int J Obes Relat Metab Disord. 1997; $21(9): 775-782$.

[22]. Desalu OO, Salami AK, Oluboyo PO, Olarinoye JK. Prevalence and Sociodemographic determinants of obesity among adults in an urban Nigerian population. Sahel Medical Journal. 2008; 11 (2): 61 - 64.

[23]. Likitmaskul S, Kiattisathavee P, Chaichanwatanakul K, Punnakanta L, Angsusingha K, Tuchinda C. Increasing prevalence of type 2 diabetes mellitus in Thai children and adolescents associated with increasing prevalence of obesity. J Pediatr Endocrinol Metab. $2003 ; 16(1): 71-77$.

[24]. Dai S, Harrist RB, Rosenthal GL, Labarthe DR. Effects of body size and body fatness on left ventricular mass in children and adolescents : Project Heartbeat! Am J Prev Med. 2009; 37: (1 suppl) S97 - 104.

[25]. Sivanandaram S, Sinaiko AR, Jacobs DR Jr, Steffen L, Moran A, Steinberger J. Relation of increase in adiposity to increase in left ventricular mass from childhood to young adulthood. Am J Cardiol. 2006; 98 (3) : $411-415$.

[26]. Brown A, Saihpush M. Risk factors for overweight and obesity: results from the 2001 National Health Survey. Public Health 2007; 121: $603-613$.

[27]. Tur JA, Serra-Majem L, Romaguera D, Pons A. Profile of overweight and obese people in a Mediterranean region. Obes Res. 2005; $13: 527-536$

[28]. Puoane T, Styne K, Bradshaw D, Laubscher R, Fouwe J et al. Obesity in South Africa : the South African demographic health survey. Obes Res 2002; 10: 1038 - 1048 .

[29]. Fernald LC. Socioeconomic status and body mass index in low - income Mexican adults. Soc Sc Med 2007; 64: 2030 - 2042.

Table 1 - Demographic characteristics of the study population

\begin{tabular}{|l|l|l|l|l|}
\hline Variable & $\begin{array}{l}\text { Male } \\
\mathbf{n}=\mathbf{3 1 5} \\
\text { Mean (SD) }\end{array}$ & $\begin{array}{l}\text { Female } \\
\mathbf{n}=\mathbf{1 5 6} \\
\text { Mean (SD) }\end{array}$ & t-test & p-value \\
\hline Age(years) & $28.83(9.38)$ & $28.30(8.53)$ & 0.60 & 0.551 \\
\hline Weight $(\mathrm{kg})$ & $67.76(10.77)$ & $66.03(13.35)$ & 1.51 & 0.131 \\
\hline Height $(\mathrm{m})$ & $1.69(0.08)$ & $1.64(0.33)$ & 2.59 & $0.010^{*}$ \\
\hline BMI $\left(\mathrm{kg} / \mathrm{m}^{2}\right)$ & $25.17(4.60)$ & -3.50 & $0.001^{*}$ \\
\hline
\end{tabular}

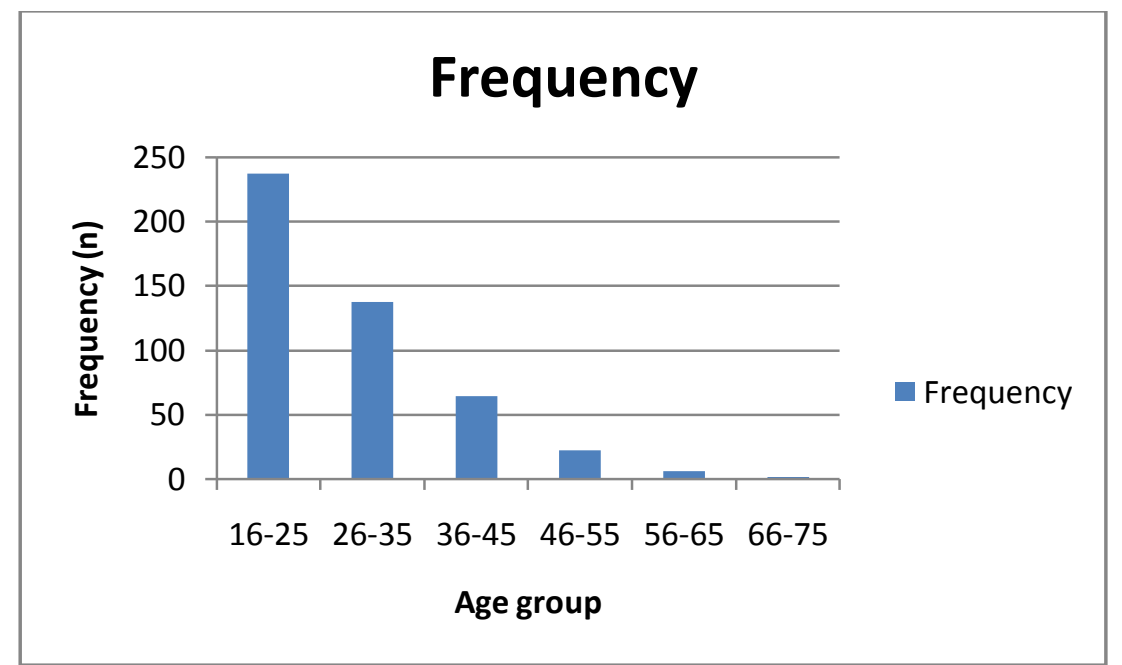

Figure 1 - Age distribution of the study population

Table 2 - The distribution of body mass index in the study population

\begin{tabular}{|l|l|l|}
\hline Classification & Frequency (n) & Percentage (\%) \\
\hline Underweight & 8 & 1.7 \\
\hline Normal & 296 & 63.0 \\
\hline Overweight & 124 & 26.2 \\
\hline Obese & 43 & 9.1 \\
\hline Total & $\mathbf{4 7 1}$ & $\mathbf{1 0 0}$ \\
\hline
\end{tabular}




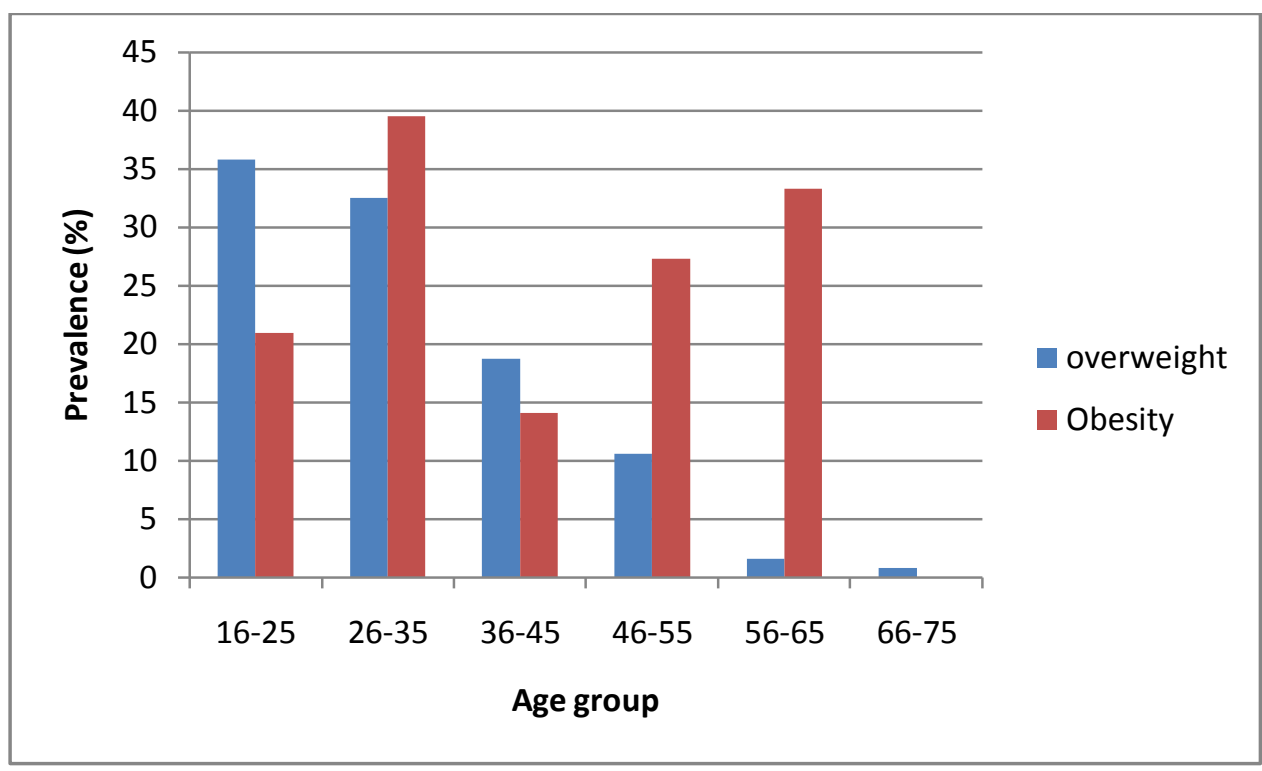

Figure 2 - Prevalence of overweight and obesity by age group 